\title{
THE EFFECT OF HYPERTENSIVE EPISODES AND CARDIAC HYPERTROPHY ON THE CANINE CARDIAC BAROREFLEX
}

\author{
Bronwyn A. Kingwell, Lisa Krause and Stevo Julius \\ Department of Internal Medicine, Division of Hypertension, University of Michigan, \\ Ann Arbor, Michigan, USA
}

\begin{abstract}
SUMMARY
1. Left ventricular (LV) hypertrophy has been implicated in the reduction of baroreflex sensitivity present in hypertension. The aim of the current study was to investigate the mean arterial pressure-heart rate reflex (MAP-HR) in a model which induced left ventricular hypertrophy but no sustained blood pressure elevation.

2. Five mongrel dogs were exposed to transient blood pressure elevation of between 20 and 30 $\mathrm{mmHg}$, through hindlimb compression using a pneumatic pressure suit, for $7 \mathrm{~h}$ per day, 6 days per week for 6 weeks. Resting blood pressure was not altered by the 6 week hindlimb compression intervention.

3. Echocardiographically determined LV mass (mean \pm s.e.m.) was $116.0 \pm 7.4 \mathrm{~g}$ prior to hindlimb compression (baseline) and elevated to $125.4 \pm 8.1 \mathrm{~g}(P=0.003)$ after 6 weeks of compression. A reduction in the early (E) to late (A) transmitral diastolic flow ratio (E/A) from $1.80 \pm 0.06$ at baseline to $1.54 \pm 0.09(P=0.037)$ after the 6 week intervention suggested that cardiac compliance was reduced.

4. The maximum gain of the MAP-HR reflex, studied using the 'steady-state' drug technique, when blood pressure was normal, showed a trend for reduction from $3.85 \pm 0.43$ beats $/ \mathrm{min}$ per $\mathrm{mmHg}$ at baseline to $3.10 \pm 0.45$ beats $/ \mathrm{min}$ per $\mathrm{mmHg}(P=0.067)$ after 6 weeks of compression. This gain reduction became significant after $\beta$-adrenoceptor blockade with propranolol $(3.13 \pm 0.55$ vs $2.32 \pm 0.25$ beats/min per $\mathrm{mmHg} ; P=0.039$ ). Covariant analysis showed a significant inverse correlation between LV mass and maximum gain $(r=0.96 ; P<0.001)$ during the 6 week compression period.

5. The MAP-HR reflex changes in this model mimic those present in hypertension and implicate cardiac hypertrophy as one possible mediator.
\end{abstract}

Key words: baroreflexes, blood pressure control, hypertension, left ventricular hypertrophy, nitroprusside, phenylephrine, vasoactive drug.

\section{INTRODUCTION}

Baroreflex sensitivity is reduced in both animal models of hypertension and human hypertension (Bristow et al. 1969; Korner et al. 1974; Mancia et al. 1986; Head \& Adams 1988). More recent human studies indicate

Correspondence: Dr Bronwyn Kingwell, Alfred and Baker Medical Unit, Baker Medical Research Institute, Commercial Rd, Prahran, Vic., 3181, Australia.

Received 18 November 1992; revision 6 August 1993; accepted 19 October 1993. that the major component of the blood pressure-heart rate reflex deficit in hypertension is parasympathetic (Kingwell et al. 1993). Whether the baroreflex abnormalities in hypertension originate from modification of the afferent, central or the efferent neuroeffector mechanism is less well understood, due in part to the difficulties in isolating one component of an integrated reflex system in a conscious whole animal study. Recently however it has been suggested that cardiac hypertrophy is a major contributor to the parasympathetic blood pressure-heart rate baroreflex deficit present in spontaneously hypertensive rats 
(Minami \& Head 1993). The aim of the current study was to further investigate the possibility of a mediatory role for cardiac hypertrophy in the baroreflex deficit present in hypertension using a model of cardiac hypertrophy dissociated from chronic hypertension.

A canine model developed by Julius and his coworkers in 1982 (Julius et al. 1982) was used to induce cardiac hypertrophy through transient elevation of blood pressure by non-invasive compression of the hindlimbs using a pneumatic pressure suit. Hindlimb compression elicits a somatopressor reflex which increases sympathetic drive to the heart and vasculature (Osterziel et al. 1984). Dogs subjected to between 6 and 9 weeks of daily, $6 \mathrm{~h}$ compressions develop significant left ventricular (LV) hypertrophy but no sustained blood pressure elevation (Julius et al. 1989). This model provides the basis for the study of the effects of transient hypertensive episodes, but also the effects of cardiac hypertrophy, on circulatory regulation under circumstances where blood pressure is normal and there are no other mechanical disturbances to the circulation.

The purpose of the present study was to document the effects of both the transient hypertensive episodes and the associated LV hypertrophy on the mean arterial pressure-heart rate (MAP-HR) baroreflex. Overall reflex properties were studied with both the sympathetic and vagal effectors functioning as well as the vagal component alone after $\beta$-adrenergic blockade with propranolol (Head \& McCarty 1987; Courneya \& Woods 1990).

\section{METHODS}

\section{Study design}

Studies were performed on five adult female mongrel dogs (mean weight \pm s.e.m. prior to study $22.1 \pm 1.6$ $\mathrm{kg}$ ) before and after chronic hindlimb compression. During an initial 2-4 week period animals were trained to stand quietly in a supportive sling and were familiarized with the hindlimb compression procedure. Each dog underwent surgery for placement of arterial and venous catheters and a 10 day surgical recovery period ensued before experiments commenced. Echocardiography, MAP-HR reflex assessments and blood pressure monitoring studies were made in duplicate in all dogs (baseline studies) with a 3 week separation between studies. These duplicate studies established the reproducibility of the experimental procedures and served as time controls for the studies performed after hindlimb compression. All measurements were repeated after dogs had been exposed to 3 and 6 weeks of chronic hindlimb compression.

\section{Surgical procedures}

Animals were pre-medicated for surgery with atropine sulfate $(0.04 \mathrm{mg} / \mathrm{kg}, \mathrm{i} . \mathrm{m}$.) and induced with thiamylal sodium $(\sim 17.5 \mathrm{mg} / \mathrm{kg}$, i.v.). Anaesthesia was maintained with a halothane, $\mathrm{O}_{2}$ mixture at a concentration between 0.5 and $3.0 \%$ ( $\mathrm{vol} / \mathrm{vol}$ ) via a Vetaflex 5 (Pitman-Moore) inhalant anaesthetic machine. An arterial catheter was placed in the aorta through the left omocervical artery which arises from the subclavian artery and a venous catheter was placed in the left jugular vein. Both catheters (VAP Norfolk Medical Products Inc., Skokie, IL, USA) had an internal diameter of $1 \mathrm{~mm}$.

\section{Hindlimb compression}

After completion of baseline measurements, conscious, unsedated animals were subjected to two $3.5 \mathrm{~h}$ hindlimb compression sessions separated by a $1 \mathrm{~h}$ interval (a total of $7 \mathrm{~h} /$ day), 6 days per week for 6 weeks. Hindlimb compression was achieved in the standing posture using a pressure suit (Jobst pneumatic appliance, Toledo, OH, USA) connected to a Hokanson E-20 rapid cuff inflator (Issaquah, WA, USA) which maintained the pressure in the suit between 30 and 40 $\mathrm{mmHg}$ and induced a blood pressure elevation of between 20 and $30 \mathrm{mmHg}$.

\section{Blood pressure monitoring}

Intra-arterial blood pressure and heart rate was monitored continuously in four $2 \mathrm{~h}$ sessions, in the absence of hindlimb compression. Two sessions were completed prior to commencement of the study and other sessions were after 3 and 6 weeks of compression. Intra-arterial blood pressure was measured with a Hewlett Packard (Palo Alto, CA, USA) 1290C straingauge manometer connected to an $8805 \mathrm{D}$ signal conditioner. The signal was digitized (Po-Ne-Mah Inc., Storrs, CT, USA) at $250 \mathrm{~Hz}$ and beat by beat measures of mean arterial pressure and heart rate were averaged for the entire monitoring session.

\section{Cardiac structure and function}

Two-dimensional echocardiography and Doppler ultrasound measurements were obtained using a Hewlett Packard series 40 ultrasound imaging machine (Andover, MA, USA) with a $2.25 \mathrm{MHz}$ transducer. All measurements were made by the same experienced technician (L. K.). The unsedated dogs were trained to rest on their right sides in a supine position, on an examination table that had a section removed to allow for transducer placement. The transducer was 
positioned from below, at the area of the maximal cardiac impulse. Short-axis images were obtained at the mid-papillary muscle level of the left ventricle. Long axis images were obtained with the transducer rotated until the longest axial length was visualized.

The pulsed Doppler examination of the mitral inflow was made using the apical four chamber view. The Doppler sample volume was placed in the mitral valve funnel, to the left ventricular side of the mitral annulus. The sample volume marker was adjusted so as to position the ultrasound beams parallel to the LV inflow. All of the Doppler flow velocities were recorded with a sample volume of $5 \mathrm{~mm}$ width. The Doppler waveforms were recorded for at least 10 continuous cardiac cycles at a paper speed of $50 \mathrm{~mm} / \mathrm{s}$.

A Diasonics minicomputer-based video digitizing system was used for two-dimensional echocardiographic analysis. End diastolic frames were selected for analysis with the use of the R wave in lead II as a marker for end diastole. Endocardial and epicardial borders for six consecutive sinus beats, using the cross-sectional view at the papillary and mitral levels, were carefully traced using a light pen directly on the video display. Left ventricular length was determined by measuring the length from the apex to the mitral valve using the long axis view. Areas were determined by computer after outlining with the light pen. Volumes were derived from equation (1):

$$
\mathrm{LVV}=5 ; 6 \mathrm{IA} \times \mathrm{IL}
$$

where $\mathrm{LVV}=$ left ventricular volume; $\mathrm{IA}=$ internal (endocardial) area; $\mathrm{IL}=$ internal length (Feigenbaum 1981). Mass was calculated by subtracting endocardial volumes from epicardial volumes and multiplying the result by the specific gravity of myocardial muscle [equation (2)].

$$
\mathrm{LV} \text { mass }=(\mathrm{LVEV}-\mathrm{LVIV}) \times \mathrm{SG}
$$

where $\mathrm{LV}$ mass = left ventricular mass, $\mathrm{LVEV}=$ left ventricular external or epicardial volume, $\mathrm{LVIV}=$ left ventricular internal or endocardial volume, $\mathrm{SG}=$ specific gravity of cardiac muscle $\left(1.04 \mathrm{~g} / \mathrm{cm}^{3}\right)$.

At the end of experiments all animals were killed and the echocardiographic measurements of LV mass verified. The heart was carefully dissected and all epicardic fat was removed. The mass of the left ventricle was measured by an independent observer and correlated well with echocardiographically calculated LV mass $(r=0.84 ; P<0.01)$.

\section{Construction of MAP-HR curves}

Reflex heart rate responses were measured to 'steady- state' changes in intra-arterial MAP evoked by injection of vasoactive drugs (Korner et al. 1974; Head \& Adams 1988; Kingwell et al. 1991). Phenylephrine (Neo-synephrine, Winthrop, New York, NY, USA) injections of varying dosage $(50-400 \mu \mathrm{g}$ in $1-2 \mathrm{~mL}$ of $0.9 \% \mathrm{NaCl}$ ) were used to study the bradycardia response to a range of MAP increases (resting MAP $+\sim 30 \mathrm{mmHg}$ ). Nitroprusside (Nitropress, Abbott, Chicago, IL, USA) injections of varying dosage (50-2000 $\mu \mathrm{g}$ in 1-2 $\mathrm{mL}$ of $5.0 \%$ dextrose) were alternated with the phenylephrine to study the tachycardia response to a physiological range of MAP decreases (resting MAP $-\sim 30 \mathrm{mmHg}$ ). Each MAP change was maintained for $\sim 30 \mathrm{~s}$ to ensure adequate time for both sympathetic and vagal effectors to react (Wang \& Borison 1947; Coleman 1980). The mean values over the final $10-15 \mathrm{~s}$ were taken as the 'steadystate' MAP and heart rate values. Responses to 10-12 MAP changes of small $(\sim 3-5 \mathrm{mmHg})$, medium $(\sim 6-15 \mathrm{mmHg})$ and large $(\sim 16-35 \mathrm{mmHg}) \mathrm{mag}-$ nitude were recorded in each direction. MAP and heart rate values were allowed to return to resting between the drug infusions.

During MAP-HR reflex assessments, intra-arterial blood pressure was monitored using a Statham P23 DB pressure transducer and a Hewlett Packard pressure amplifier $8805 \mathrm{C}$. The mean blood pressure was recorded continuously on an 8 channel Gould recorder TA600 together with heart rate which was triggered from the arterial pressure pulse.

\section{Protocol}

For each measurement period (that is, the two baseline measurements, and after 3 and 6 weeks of hindlimb compression) experiments were performed over 3 days. On the first day echocardiography was followed by a $2 \mathrm{~h}$ blood pressure monitoring session. The MAP-HR reflex was studied on the two subsequent days, firstly against a constant background infusion of $0.9 \% \mathrm{NaCl}$ and secondly after $\beta$-adrenoceptor blockade with a $1 \mathrm{mg} / \mathrm{kg}$ bolus of propranolol followed by a 0.05 $\mathrm{mg} / \mathrm{min}$ infusion during the experiment (Pace 1978; Head \& McCarty 1987; Courneya \& Woods 1990). The blockade was considered effective if the heart rate response to a $10 \mu \mathrm{g}$ bolus of isoprenaline was abolished.

\section{Modelling of the MAP-HR reflex}

The MAP-HR reflex data was modelled to a symmetrical sigmoidal relationship as described previously (Blake \& Korner 1981; Head \& McCarty 1987; Kingwell et al. 1991) where: 


$$
H R=L P+(U P-L P) /\left[1+e^{\mathbf{C}_{(M A P}-B_{50)}}\right]
$$

and $\mathrm{LP}=$ lower plateau; $\mathrm{UP}=$ upper plateau; $\mathrm{C}=$ curvature coefficient; $\mathrm{BP}_{50}=$ median blood pressure; $(U P-L P)=$ HR Range. The function is symmetrical about the $\mathrm{BP}_{50}$ which represents the blood pressure at the mid-point between the two plateaus. The sigmoidal curve is constrained to pass through the resting heart rate $\left(\mathrm{HR}_{\mathrm{r}}\right)$ and resting $\mathrm{MAP}\left(\mathrm{MAP}_{\mathrm{r}}\right)$ values since all MAP and $H R$ changes are calculated from this point.

The maximum gain $\left(\mathrm{G}_{\max }\right)$ is the slope of the reflex at the mid-point of the curve $\left(\mathrm{BP}_{50}\right)$.

$$
\mathrm{G}_{\max }=-\mathrm{C} \times \mathrm{HR} \text { Range } / 4.0
$$

The gain at the resting blood pressure $\left(G_{\text {rest }}\right)$ was also calculated at the resting MAP using equation (5).

$\mathrm{G}=\mathrm{HR}$ Range $\left[\left\{C \mathrm{e}^{\mathrm{C}\left(\mathrm{MAP}-\mathrm{BP}_{50}\right)}\right\} /\left\{1+\mathrm{e}^{\mathrm{C}\left(\mathrm{MAP}-\mathrm{BP}_{50}\right)}\right\}^{2}\right]$

$\mathrm{G}_{\mathrm{rest}}$ is most relevant to the small physiological blood pressure fluctuations which occur constantly.

The curvature coefficient ' $C$ ' reported in equations (3), (4) and (5) represents an inverse measure of the MAP range over which the reflex is sensitive. The reciprocal of ' $C$ ' gives an absolute measure of the blood pressure operating range termed the MAP domain $\left(\right.$ MAP $_{d}$ ) which is given by:

$$
\text { MAP }_{d}=2.773 / \mathrm{C}
$$

The MAP $_{d}$ represents the MAP range corresponding to a reduction in heart rate from 80 to $20 \%$ of the HR Range (Kingwell et al. 1991).

Finally, the location of the resting HR was expressed as a percentage of the HR Range $\left(\mathrm{HR}_{\mathrm{r}} \%\right)$ and is given by:

$$
\mathrm{HR}_{\mathrm{r}} \%=\left(\mathrm{HR}_{\mathrm{r}}-\mathrm{LP}\right) \times 100 /(\mathrm{UP}-\mathrm{LP})
$$

This value gives a measure of the position of the resting heart rate relative to the lower plateau and as a proportion of the HR Range.

\section{Statistics}

Paired $t$-tests were used to compare duplicate baseline experiments. $P$ values for these comparisons ranged from 0.223 to 0.893 so the two baseline experiments were averaged to give a single baseline value (Table 1). All parameters during the 6 week intervention were compared using two way analysis of variance and partitioning of the treatment sums of squares. The linear coefficients $-1,0,1$ which correspond to a $1^{\circ}$ polynomial compared baseline and week 6 parameters and tested for a linear association with time (Snedecor
\& Cochran 1980). To remove 'between dog effects' covariant analysis was used to examine the relationship between LV mass and maximum gain. The line of symmetry was derived using Model II regression which accounts for the sampling error in both variables (Brace 1977). All values are presented as mean \pm s.e.m.

\section{RESULTS}

\section{Effect of chronic hindlimb compression on resting blood pressure, heart rate and body weight}

Six weeks of hindlimb compression induced no change in resting MAP which was $101.4 \pm 4.8 \mathrm{mmHg}$ at baseline, $97.6 \pm 1.8 \mathrm{mmHg}$ after 3 weeks of compression and $99.2 \pm 5.7 \mathrm{mmHg}$ after 6 weeks. Resting heart rate was $80.4 \pm 11$ beats $/ \mathrm{min}$ at baseline, $78.6 \pm 6.5$ beats $/ \mathrm{min}$ at week 3 and $72.0 \pm 4.2$ beats/ $\min (P=0.418)$ at week 6 . Bodyweight remained stable throughout the study (baseline $=22.1 \pm 1.6$ $\mathrm{kg}$; week $6=21.9 \pm 1.7 \mathrm{~kg}$ ).

\section{Effect of chronic hindlimb compression on cardiac structure and function}

$\mathrm{LV}$ mass was $116.0 \pm 7.4 \mathrm{~g}$ at baseline, $121.4 \pm 8.0 \mathrm{~g}$ after 3 weeks of hindlimb compression and $125.4 \pm$ $8.1 \mathrm{~g}$ after 6 weeks $(P=0.003$; Fig. 1$)$. Consistent with development of concentric LV hypertrophy, epicardial volume increased from $159.1 \pm 12.4 \mathrm{~cm}^{3}$ to $169.1 \pm 14.5 \mathrm{~cm}^{3}$ at 3 weeks and $174.4 \pm 11.4 \mathrm{~cm}^{3}$ at 6 weeks $(P=0.004)$, while endocardial volume was not altered by the 6 week compression period $(P=0.679$; Fig. 1).

The early (E) to late (A) transmitral diastolic flow ratio (E/A), an index of ventricular compliance, was reduced with 6 weeks of compression from $1.80 \pm 0.06$ to $1.54 \pm 0.09$ (Fig. $1, P=0.037$ ). Heart rate, a major determinant of $\mathrm{E} / \mathrm{A}$, was not different pre- and postcompression. No significant changes in deceleration time or cardiac output were observed.

\section{Effect of chronic hindlimb compression on MAP-HR reflex properties}

Duplicate baseline MAP-HR reflex assessments performed 3 weeks apart attested to the reproducibility of the 'steady-state' drug method of baroreflex function assessment and also to baroreflex stability over time. There was no significant difference between any of the parameters describing the reflex at these assessments. The results for upper and lower plateaus and maximum reflex gain are reported in Table 1. 
Hindlimb compression for both 3 and 6 weeks progressively reduced the HR Range of the reflex through reduction in the upper heart rate plateau (Table 2; Fig. 2, upper panels). The lower plateau and the sensitive pressure range of the reflex as indicated by the $\mathrm{MAP}_{\mathrm{d}}$ values were unchanged at both 3 and 6 weeks. $\beta$-Adrenergic blockade abolished the reduction in upper plateau suggesting a sympathetic origin (Table 3).

Maximum gain $\left(\mathrm{G}_{\max }\right.$, which is the gain at the mid-

Table 1. MAP-HR reflex parameters obtained in duplicate baseline assessments

\begin{tabular}{lcccccccccc}
\hline & \multicolumn{4}{c}{ Vagus and sympathetic } & \multicolumn{4}{c}{ Vagus only } \\
& \multicolumn{1}{c}{ Base 1 } & Base 2 & $P$ & Base 1 & Base 2 & $P$ \\
\hline Upper plateau (beats/min) & 160 & $(13)$ & 175 & $(8)$ & 0.315 & 135 & $(12.0)$ & 134 & $(11)$ & 0.893 \\
Lower plateau (beats/min) & 56.5 & $(9.0)$ & 52.6 & $(9.3)$ & 0.887 & 51.6 & $(7.3)$ & 48.6 & $(6.8)$ & 0.223 \\
$\mathrm{G}_{\max }$ (beats/min per $\left.\mathrm{mmHg}\right)$ & 3.99 & $(0.39)$ & 3.70 & $(0.49)$ & 0.318 & 3.27 & $(0.76)$ & 3.00 & $(0.44)$ & 0.911 \\
\hline
\end{tabular}

Means (s.e.m.) for MAP-HR reflex parameters obtained at two baseline assessments (Base 1 and Base 2) separated by 3 weeks $(n=5)$. These values were obtained with both the vagal and sympathetic effectors functioning (vagus and sympathetic) and after $\beta$-adrenoceptor blockade (vagus only). $\mathrm{G}_{\max }=$ maximum gain.

Table 2. MAP-HR reflex parameters with both sympathetic and vagal effectors functioning

\begin{tabular}{|c|c|c|c|c|c|c|c|}
\hline \multirow[b]{3}{*}{ Upper plateau (beats/min) } & \multicolumn{6}{|c|}{ Vagus and sympathetic } & \multirow{3}{*}{$\frac{P}{0.035}$} \\
\hline & \multicolumn{2}{|c|}{ Base } & \multicolumn{2}{|c|}{ Week 3} & \multicolumn{2}{|c|}{ Week 6} & \\
\hline & 167 & $(8)$ & 151 & (9) & 145 & (19) & \\
\hline Lower plateau (beats/min) & 54.6 & (9) & 51.1 & (12) & 54 & (12) & 0.881 \\
\hline HR Range (beats/min) & 113 & (5) & 100 & $(8)$ & 91 & (11) & 0.011 \\
\hline $\mathrm{G}_{\max }$ (beats/min per $\mathrm{mmHg}$ ) & 3.85 & $(0.43)$ & 3.16 & $(0.39)$ & 3.10 & $(0.45)$ & 0.067 \\
\hline $\mathrm{G}_{\text {rest }}$ (beats/min per $\mathrm{mmHg}$ ) & 1.79 & $(0.09)$ & 1.60 & $(0.17)$ & 2.34 & $(0.50)$ & 0.236 \\
\hline $\mathrm{MAP}_{\mathrm{d}}(\mathrm{mmHg})$ & 21.2 & $(1.7)$ & 23.7 & $(2.4)$ & 21.1 & $(2.0)$ & 0.957 \\
\hline $\mathrm{BP}_{50}(\mathrm{mmHg})$ & 86.2 & (3.3) & 84.5 & $(5.0)$ & 84.8 & (3.6) & 0.783 \\
\hline $\mathrm{HR}_{\mathrm{r}} \%$ & 15 & $(2)$ & 16 & (3) & 30 & (7) & 0.039 \\
\hline
\end{tabular}

Mean (s.e.m.) for MAP-HR reflex parameters obtained at baseline, 3 and 6 weeks of compression with both vagal and sympathetic effectors functioning. Base $=$ average of two determinations prior to compression; Week $3=$ measurements made after 3 weeks of hindlimb compression; Week $6=$ measurements made after 6 weeks of hindlimb compression; $\mathrm{G}_{\max }=$ maximum gain; $\mathrm{G}_{\text {rest }}=$ gain at the resting point; $M A P_{\mathrm{d}}=$ MAP difference to alter heart rate from 80 to $20 \%$ of the $\mathrm{HR}$ Range; $\mathbf{B P}_{50}=$ median blood pressure; $\mathrm{HR}_{\mathrm{r}} \%=$ resting heart rate as a percentage of $\mathrm{HR}$ Range. $P$ values are for Week 6 comparisons with Base (linear trends). $(P<0.05 ; n=5$.)

Table 3. MAP-HR reflex parameters obtained with only vagal effectors functioning

\begin{tabular}{|c|c|c|c|c|c|c|c|}
\hline \multirow[b]{3}{*}{ Upper plateau (beats/min) } & \multicolumn{7}{|c|}{ Vagus Only } \\
\hline & \multicolumn{2}{|c|}{ Base } & \multicolumn{2}{|c|}{ Week 3} & \multicolumn{2}{|c|}{ Week 6} & \multirow{2}{*}{$\frac{P}{0.703}$} \\
\hline & 135 & (11) & 115 & (6) & 130 & $(8)$ & \\
\hline Lower plateau (beats/min) & 50.1 & (7) & 47.9 & $(8)$ & 49.1 & (10) & 0.867 \\
\hline HR Range (beats/min) & 84.4 & (14) & 66.8 & (5) & 81.0 & $(5.1)$ & 0.771 \\
\hline $\mathrm{G}_{\max }$ (beats/min per $\mathrm{mmHg}$ ) & 3.13 & $(0.55)$ & 2.23 & $(0.33)$ & 2.32 & $(0.25)$ & 0.039 \\
\hline $\mathrm{G}_{\text {rest }}$ (beats/min per $\mathrm{mmHg}$ ) & 1.81 & $(0.31)$ & 1.58 & $(0.30)$ & 1.50 & $(0.16)$ & 0.295 \\
\hline $\mathrm{MAP}_{\mathrm{d}}(\mathrm{mmHg})$ & 20.3 & $(2.4)$ & 23.5 & $(5.1)$ & 25.3 & $(2.8)$ & 0.082 \\
\hline $\mathrm{BP}_{50}(\mathrm{mmHg})$ & 84.0 & $(2.1)$ & 89.0 & $(6.1)$ & 83.8 & $(5.1)$ & 0.972 \\
\hline $\mathrm{HR}_{\mathrm{r}} \%$ & 20 & (3) & 29 & (7) & 23 & (5) & 0.670 \\
\hline
\end{tabular}

Mean (s.e.m.) for MAP-HR reflex parameters obtained at baseline, 3 and 6 weeks of compression with only the vagal effectors functioning (after $\boldsymbol{\beta}$-adrenergic blockade). Base $=$ average of two determinations prior to compression; Week $3=$ measurements made after 3 weeks of hindlimb compression; Week $6=$ measurements made after 6 weeks of hindlimb compression; $\mathrm{G}_{\max }=$ maximum gain; $\mathrm{G}_{\mathrm{rest}}=$ gain at the resting point; $\mathbf{M A P}_{\mathrm{d}}=$ MAP difference to alter heart rate from 80 to $20 \%$ of the HR Range; $\mathrm{BP}_{50}=$ median blood pressure; $\mathrm{HR}_{\mathrm{r}} \%=$ resting heart rate as a percentage of $\mathrm{HR}$ Range. $P$ values are for Week 6 comparisons with Base (linear trends). $(P<0.05 ; n=5$.) 
point of the curve) showed a trend for reduction during the 6 week compression period (Fig. 2, lower panels). This trend became significant after $\beta$-adrenergic blockade with propranolol. In the presence of $\beta$-adrenergic blockade, none of the other baroreflex parameters were altered during the 6 week study period.

Hindlimb compression for 6 weeks also resulted in an increase in $\mathrm{HR}_{r} \%$ from $15 \pm 2 \%$ to $30 \pm 7 \%(P=$ 0.025 ), indicating that the resting point occurred at a greater percentage of the HR Range after compression. This was due in part to the compression induced reduction in the HR Range. The net result was relocation of the resting point on a steeper portion of the curve after 6 weeks of hindlimb compression. This is illustrated by the solid curves in the lower panels of Fig. 2 where the resting point, shown as a solid circle, is located closer to the mid-point of the curve after 6 weeks of hindlimb compression compared with baseline. Since the curve is steeper towards the centre, the central shift of the resting point resulted in no change
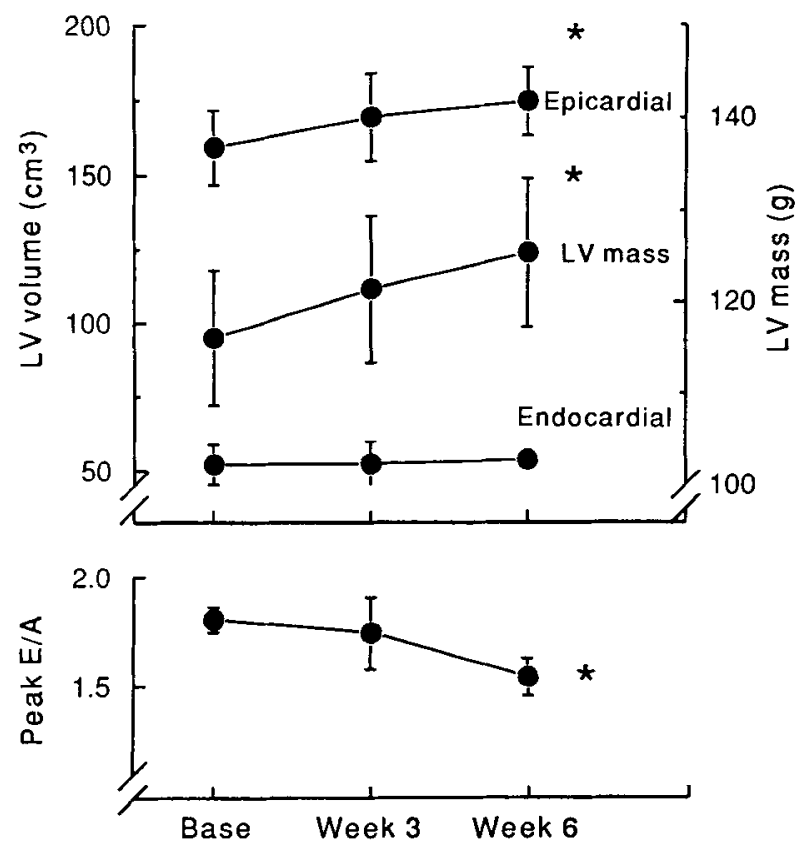

Fig. 1. Upper panel: LV mass, LV end-diastolic endocardial and epicardial volumes at baseline (Base), and after 3 weeks (Week 3) and 6 weeks (Week 6) of hindlimb compression. Lower panel: Early (E) to late (A) transmitral diastolic flow ratio (peak E/A) at baseline, and after week 3 and week 6 of compression. Error bars represent the s.e.m. *Significant differences between Base and Week 6 (linear trends; $P<0.05$;

$$
n=5) \text {. }
$$

of the gain at the resting point $\left(\mathrm{G}_{\mathrm{rest}}\right)$, despite the tendency for reduction in the maximum gain (Fig. 2, lower panels).

Covariant analysis between $\mathrm{LV}$ mass and maximum gain revealed a significant relationship with the line of symmetry calculated from Model II regression: $\mathrm{G}_{\max }=18.70-0.1267 \times \mathrm{LV}$ mass $(r=0.96$; $P<0.001$; Fig. 3).

\section{DISCUSSION}

The major findings of this study were that repeated exposure to elevated blood pressure was associated with reduction in both the maximum tachycardia in response to blood pressure reduction and a trend for reduction in the maximum MAP-HR reflex sensitivity. After $\beta$-adrenergic blockade the reduction in maximum tachycardia was absent, indicating a sympathetic origin, but the reduction in maximum sensitivity became significant, suggesting a vagal origin. The changes observed in the MAP-HR reflex occurred concurrently with development of concentric LV hypertrophy as evidenced by an increase in both LV mass and epicardial volume while endocardial volume remained unchanged and E/A ratio, an index of cardiac compliance decreased (Laufer et al. 1986, 1989). Reflex changes occurred in the absence of a chronic change in blood pressure. The negative correlation between maximum gain and LV mass suggests that cardiac hypertrophy or related factors may play a role in mediating the blood pressure control disturbances in this model of transient hypertension.

Many groups have proposed that the baroreflex abnormalities associated with hypertension are, at least in part, the result of cardiac hypertrophy (Trimarco et al. 1986, 1989; Grassi et al. 1988; Giannattasio et al. 1989; Minami \& Head 1993) but in the past it has been difficult to isolate the effects of hypertrophy from high blood pressure per se. In the current study we observed impairment in the vagal component of reflex sensitivity associated with development of $\mathrm{LV}$ hypertrophy but in the presence of normal resting blood pressure. The reflex changes observed in this model are similar to those of human hypertension (Korner et al. 1974; Eckberg 1979) and in various experimental models of hypertension including the renal hypertensive rabbit (West \& Korner 1974) and in the spontaneously hypertensive rat (Ricksten \& Thoren 1981; Head \& Adams 1988).

The linear association between LV mass and maximum reflex sensitivity may provide useful insight into the origin of the reflex changes implicating either cardiac hypertrophy or alternatively $L V$ mass may be 

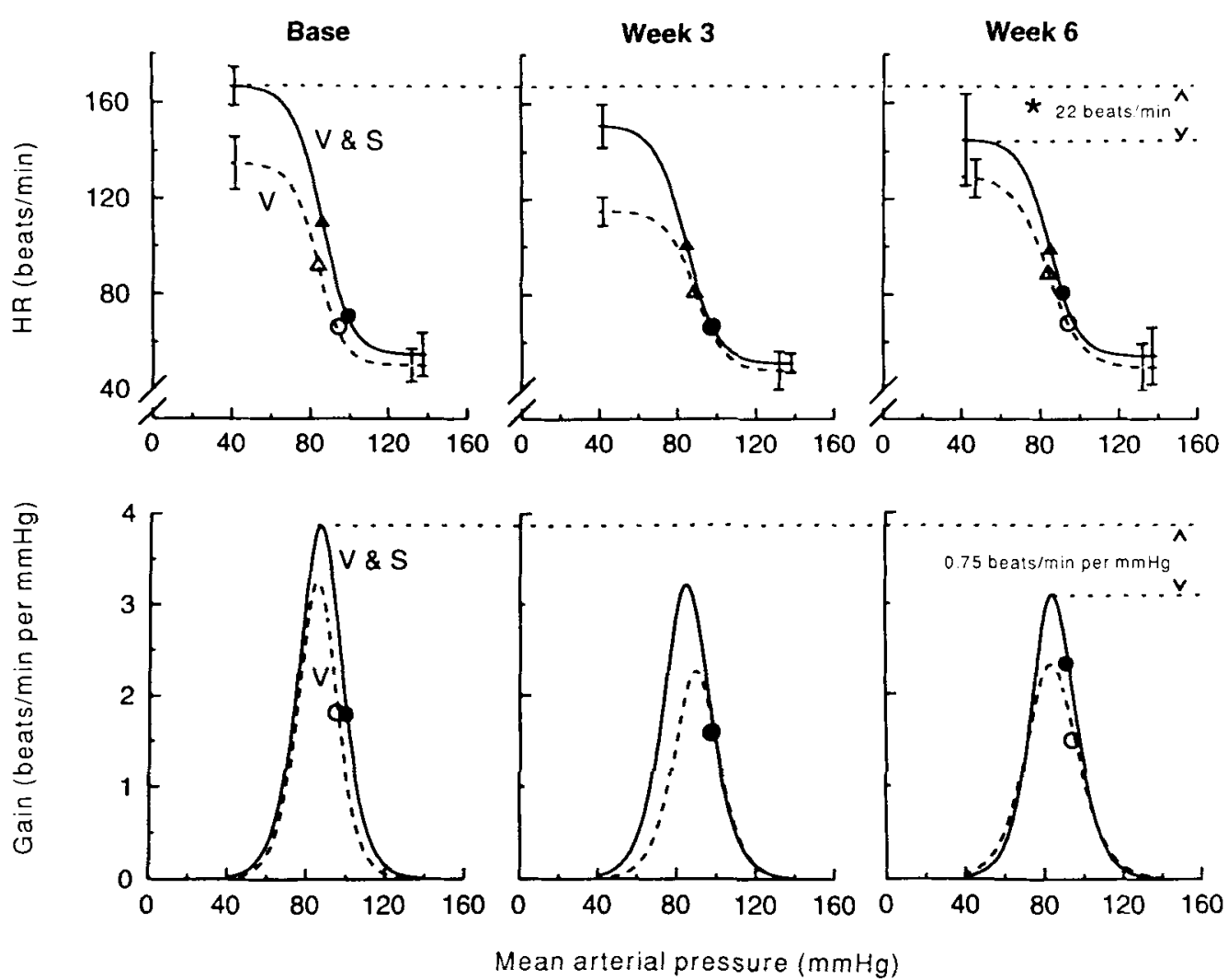

Fig. 2. Upper panels: MAP-HR reflex curves at baseline (Base), and after Week 3 and Week 6 of hindlimb compression. Lower panels: Corresponding MAP-gain plots. The solid lines represent the reflex with both vagal and sympathetic effectors intact ( $\mathrm{V} \& \mathrm{~S}$ ). The $\mathrm{BP}_{50}$ and resting value for these curves are shown as solid triangles and circles, respectively. The dashed lines represent the results obltained after propranolol administration (vagal component, $\mathrm{V}$ ). The $\mathrm{BP}_{50}$ and resting value for the vagal reflex component are shown as open triangles and circles, respectively. Error bars represent the s.e.m. *Significant difference between Base and Week 6 (linear trends; $P<0.05 ; n=5$ ).

acting as a surrogate marker for related mechanisms. Cardiac receptors are mechano-sensitive receptors which could directly alter reflex function via changes in ventricular afferent activity. An increase in LV mass and a reduction in cardiac compliance would alter the afferent activity for any given pressure change. It could thus be hypothesized that concentric cardiac hypertrophy results in changes to the threshold and sensitivity of the cardiac baroreceptors and subsequently to the pattern of afferent activity reaching the central nervous system. This altered afferent input may directly influence the heart rate response or alternatively, modify central processing of the afferent input from the arterial baroreceptors and change the efferent output in this way (Abboud \& Thames 1983). However, while ventricular receptors have been reported to be spontaneously active in open chested dogs (Sleight \& Widdicombe 1965; Thoren 1977), Thames et al. (1977) reported that in closed chested animals only $20 \%$ of the ventricular afferent nerves they studied had spontaneous activity and that the others were activated only when blood pressure was abnormally elevated. LV hypertrophy is therefore more likely to modulate reflex function in response to blood pressure elevation rather than blood pressure reduction. The reduction in maximum tachycardia in response to lowered blood pressure is thus unlikely to be mediated by changes to ventricular afferent activity. Impairment of maximum gain however, was evident after abolition of the lowered maximum tachycardia by $\beta$-adrenergic blockade and may be more closely related to LV hypertrophy.

The stimuli for cardiac hypertrophy rather than cardiac hypertrophy directly may account for the reduction in maximum tachycardia. The reflex elicited by hindlimb compression elevates blood pressure through sympathetic activation to the heart and vasculature. While blood pressure elevation would have contributed to cardiac hypertrophy, sympathetic stimulation is also a probable independent trophic factor 


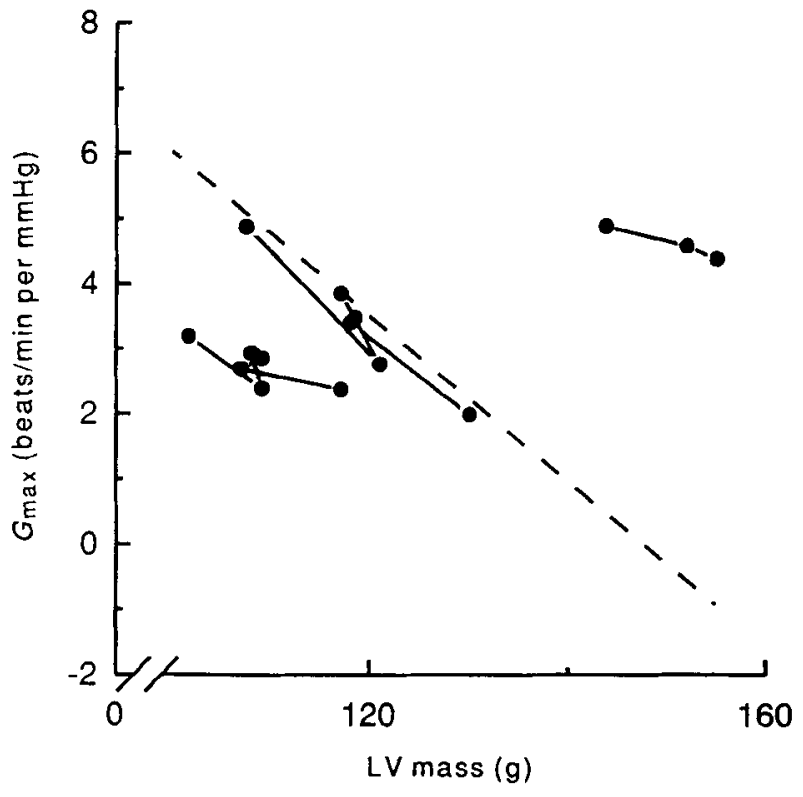

Fig. 3. LV mass versus maximum gain $\left(G_{\max }\right)$ for each animal on the three occasions studied. The dotted line represents the line of symmetry calculated using Model II regression. Covariant analysis was used to remove between dog effects and shows a strong linear association between the two variables $(r=0.96 ; P<0.001)$.

(Simpson 1983). In turn elevated sympathetic activity as occurs in many experimental models of hypertension results in a reduction in the number of $\beta$ adrenoceptors and in the production of its second messenger cyclic AMP (De Champlain 1990) which could explain the reduction in maximum tachycardia which was sensitive to $\beta$-adrenoceptor blockade. A similar reduction in maximum tachycardia has also been observed with chronic exercise training (Kingwell et al. 1992) which also intermittently elevates cardiac sympathetic activity.

A third possible mediator of the observed reflex changes is vascular hypertrophy in the region of the carotid and aortic baroreceptors. Hypertrophy of the vasculature was not measured in these animals but a few indirect indices argue against significant vessel wall thickening. It is known that the amplifying effects of vessel hypertrophy aid in the maintenance of an elevated blood pressure in hypertensives (Korner et al. 1985; Adams et al. 1990). Therefore, it would be expected that dogs might develop a chronic hypertension in the presence of significant vessel hypertrophy. Throughout the 6 week protocol, blood pressure in all dogs remained at baseline levels during measurement periods when the pressure suit was not in place. Similarly, it would be expected that the blood pressure elevation in response to suit inflation would become greater with development of vessel hypertrophy. It has, however, been documented that the change in blood pressure resulting from a constant pressure suit inflation is identical at baseline and after chronic hindlimb compression for 9 weeks (Julius $e t$ al. 1989). These observations do not of course prove the absence of vessel hypertrophy and further studies would be required to answer the question conclusively.

In summary, transient pressor episodes induced by hindlimb compression resulted in development of concentric LV hypertrophy and functional changes indicating reduced cardiac compliance. The MAPHR reflex studied during development of cardiac hypertrophy showed 'hypertension-like' characteristics including a reduction in both the magnitude of the heart rate response to blood pressure reduction and in the parasympathetic component of maximum reflex gain. The linear association between LV mass and maximum reflex gain suggests that cardiac hypertrophy or a related factor such as sympathetic activation is involved in the MAP-HR reflex changes observed. These factors may also be involved in the reflex impairments of hypertension.

\section{ACKNOWLEDGEMENTS}

It is a pleasure to thank David Brant for technical advice and assistance and Dr Grant McPherson for the computer program BARO, his modelling expertise and for assistance with preparation of the manuscript.

\section{REFERENCES}

Abboud, F. M. \& Thames, M. D. (1983) Interaction of cardiovascular reflexes in circulatory control. In: Handbook of Physiology, Sect. 2, pp. 675-753, The Cardiovascular System, Vol. III (Eds J. T. Shepherd \& F. M. Abboud), American Physiological Society, Bethesda, Maryland.

Adams, M. A., Bobik, A. \& Korner, P. I. (1990) Enalapril can prevent vascular amplifier development in spontaneously hypertensive rats. Hypertension, 16, 252-260.

Blake, D. W. \& Korner, P. I. (1981) Role of baroreceptor reflexes in the hemodynamic and heart rate responses to althesin, ketamine and thiopentone anaesthesia. Journal of the Autonomic Nervous System, 3, 55-70.

Brace, R. A. (1977) Fitting straight lines to experimental data. American Journal of Physiology, 233 (Regulatory Integrative Comp. Physiol. 3), R94-99.

Bristow, D., Honour A. J., Pickering, G. W., Sleight, P. \& Smyth H. S. (1969) Diminished baroreflex sensitivity in high blood pressure. Circulation, 39, 48-54.

Coleman, T. C. (1980) Arterial baroreflex control of heart rate in the conscious rat. American Journal of Physiology, 238 (Heart Circ. Physiol. 7), H515-520. 
Courneya, C. A. \& Woods, R. L. (1990) Lack of an effect by atrial natriuretic peptide on the baroreceptor-heart rate reflex in conscious dogs. Proceedings of the Australian Physiological Society, 21, 48P.

De Champlain, J. (1990) Pre- and postsynaptic adrenergic dysfunctions in hypertension. Journal of Hypertension, 8 (Suppl 7), S77-85.

Eckberg, D. L. (1979) Carotid baroreflex function in young men with borderline blood pressure elevation. Circulation, 59, 632-636.

Feigenbaum, H. (1981) Echocardiography, pp. 151-152. Lea and Febiger, Philadelphia.

Giannattasio, C., Seravalle, G., Bolla, G. et al. (1989) Cardiac hypertrophy impairs cardiac receptor control of circulation in man. Journal of Hypertension, 7 (Suppl. 6), S56-57.

Grassi, G., Giannattasio, C., Cleroux, J. et al. (1988) Cardiopulmonary reflex before and after regression of left ventricular hypertrophy in essential hypertension. Hypertension, 12, 227-237.

Head, G. A. \& Adams, M. A. (1988) Time course of changes in baroreceptor reflex control of heart rate in conscious SHR and WKY. Clinical and Experimental Pharmacology and Physiology, 15, 289-292.

Head, G. A. \& McCarty, R. (1987) Vagal and sympathetic components of the baroreceptor-heart rate reflex in conscious rats. Journal of the Autonomic Nervous System, 21, 203-213.

Julius, S., Li, Y., Brant, D., Krause, L. \& Buda, A. (1989) Neurogenic pressor episodes fail to cause hypertension, but do induce cardiac hypertrophy. Hypertension, 13, $422-429$.

Julius, S., Sanchez, R., Malayan, S. et al. (1982) Sustained blood pressure elevation to lower body compression in pigs and dogs. Hypertension, 4, 782-788.

Kingwell, B. A., Dart, A. M., Jennings, G. L. \& Korner, P. I. (1992) Exercise training reduces the sympathetic component of the blood pressure-heart rate baroreflex in man. Clinical Science, 82, 357-362.

Kingwell B. A., McPherson G. A., Gillies K. J., Cameron J. C., Dart A. M. \& Jennings G. L. (1993) Baroreflex function in hypertension and the effects of regular exercise. Presented to the 6th European meeting on Hypertension, Milan, Italy, 352.

Kingwell, B. A., McPherson, G. A. \& Korner, P. I. (1991) Assessment of gain of tachycardia and bradycardia responses of cardiac baroreflex. American Journal of Physiology, 260 (Heart Circ. Physiol. 29), H1254-1263.

Korner, P. I., Jennings, G. L., Esler, M. D. \& Broughton, A. (1985) A role of cardiac and vascular amplifiers in the maintenance of hypertension and the effect of reversal of cardiovascular hypertrophy. Clinical and Experimental Pharmacology and Physiology, 12, 205-209.

Korner, P. I., West, M. J., Shaw, J. \& Uther, J. B. (1974) 'Steady-state' properties of the baroreceptor-heart rate reflex in essential hypertension in man. Clinical and Experimental Pharmacology and Physiology, 1, 65-76.

Laufer, E., Jennings, G., Dewar, E., McKenzie, A. \& Korner, P. (1986) Echocardiographic measurement of left ventricular hypertrophy in untreated essential hypertension. Clinical and Experimental Pharmacology and Physiology, 13, 295-299.

Laufer, E., Jennings, G. L., Korner, P. I. \& Dewar, E. (1989) Prevalence of cardiac structural and functional abnormalities in untreated primary hypertension. Hypertension, 13, 151-162.

Mancia, G., Grassi, G., Parati, G. et al. (1986) Control of circulation by arterial baroreceptors and cardiopulmonary receptors in hypertension. Journal of Cardiovascular Pharmacology, 8 (Suppl. 5), S82-88.

Minami, N. \& Head, G. A. (1993) Relationship between cardiovascular hypertrophy and cardiac baroreflex function in spontaneously hypertensive and stroke-prone rats. Journal of Hypertension, 11, 523-533.

Osterziel, K. J., Julius, S. \& Brant, D. (1984) Blood pressure elevation during hindquarter compression in dogs is neurogenic. Journal of Hypertension, 2, 411-417.

Pace, J. B. (1978) Influence of carotid occlusion on pulmonary vascular resistance in anesthetised dogs. Proceedings of the Society of Experimental Biology and Medicine, 158, 215-219.

Ricksten, S. E. \& Thoren, P. (1981) Reflex control of sympathetic nerve activity and heart rate from arterial baroreceptors in conscious normotensive and spontaneously hypertensive rats. Clinical Science, 61, S169172.

Simpson, P. (1983) Norepinephrine-stimulated hypertrophy of cultured rat myocardial cells in an alphal adrenergic response. Journal of Clinical Investigation, 72, 732-738.

Sleight, P. \& Widdicombe, J. G. (1965) Action potentials in afferent fibres from pericardial mechanoreceptors in dogs. Journal of Physiology (London), 181, 259-269.

Snedecor, G. W. \& Cochran, W. G. (1980) Statistical Methods, 7 th edn. Iowa State University Press, Ames, Iowa.

Thames, M. D., Donald, D. E. \& Shephard J. T. (1977) Behaviour of cardiac receptors with nonmyelinated vagal afferents during spontaneous respiration in cats. Circulation Research, 41, 694-701.

Thoren, P. (1977) Characteristics of left ventricular receptors with nonmedullated vagal afferents in cats. Circulation Research, 40, 231-237.

Trimarco, B., De Luca, N., Ricciardelli, B. et al. (1986) Impaired responsiveness of the ventricular sensory receptor in hypertensive patients with left ventricular hypertrophy. Circulation, 74, 980-990.

Trimarco, B., Lembo, G., DeLuca, N. et al. (1989) Blunted sympathetic response to cardiopulmonary receptor unloading in hypertensive patients with left ventricular hypertrophy. Circulation, 80, 883-892.

Wang, S. C. \& Borison, H. L. (1947) An analysis of the carotid sinus cardiovascular reflex mechanism. American Journal of Physiology, 150, 712-721.

West, M. J. \& Korner, P. I. (1974) The baroreceptor-heart rate reflex in renal hypertension in the rabbit. Clinical and Experimental Pharmacology and Physiology, 1, 231-239. 